\title{
Development of Socio-Professional Activity of Personality in Conditions of Distance Education During Covid-19 Pandemic
}

\author{
Valerii Radul [0000-0001-5354-9142], Rostyslav Liashenko * [0000-0003-3554-8861] \\ Volodymyr Vynnychenko Central Ukrainian State Pedagogical University, Kropyvnytskyi, Ukraine \\ *r.ljashenko@gmail.com
}

\begin{abstract}
In the article, peculiarities of researching socio-professional activity have been studied. For understanding the peculiarities of socio-professional activity development, three levels of person's socio-professional activity have been proposed. Experimental data and theoretical generalizations have allowed determining certain criteria for the formation of socio-professional activity of personality. Criteria and levels of socio-professional activity have been analysed. The following criteria of socio-professional activity: personal self-realization, socio-professional orientation and socioprofessional motivation have been defined. While analyzing the development of socio-professional activity in accordance with a certain level, the research has been focused on the features of different influences of educational activities on the growth of socio-professional activity. It has been substantiated that the formation of socio-professional activity of the personality is carried out in the process of activity, communication and interaction with the educational environment through active influence on the development of socio-professional environment, through the development of interpersonal communication and improvement of psychological and pedagogical training.
\end{abstract}

Keywords: personality, distance education, socio-professional activity, individual, development.

\section{INTRODUCTION}

The unwillingness of a modern specialist to achieve a high quality of education is mainly due to the scientific orientation of personal professional attitudes, outdated knowledge, which causes the dominance of monologue teaching methods.

The knowledge-centric position of the teacher complicates the use of new educational technologies (educational discussions, educational conferences, video trainings, computer information-cognitive and control software, etc.) as forms, methods and techniques that give teaching and education dialogicity, creative orientation, emotional coloring. stimulates the formation of the subjectivity of students, the development of their cognitive independence, tolerance. The professional mentality of a modern teacher, understood as a composition of thoughts, spiritual attitudes and style of pedagogical activity, often has a negative impact on the dynamics of quantitative and qualitative development of teaching as a socio-professional group and the process of self-awareness.
When designing the content of vocational education aimed at personal development of culture, it is necessary to focus on the strategic levers of modernization of secondary school. Here it is necessary to highlight first of all those which define the content of the renewed work of the pedagogue. First, the school must become an important factor of the humanization of socio-economic relations, the formation of new life attitudes of the personality. Secondly, the potential of education must be fully used to consolidate society, preserve a single cultural space, and overcome social conflicts. Third, the school should promote the formation of a professional elite, identify and support the most gifted and talented children and youth.

The need and necessity to establish new, unknown in another living world connections with similar people, is formed on a fundamentally new basis, beginning in the process of anthropogenesis. It is caused by specific contradictions that arise in the process of essential human activity. This is a contradiction between the individual feature of production and the existence of human in general; between its individual, purposeful 
implementation and the objective need for connections with other individuals (the need determined by fixed ways of working with tools, their repeated use, the nature of the product of labor, features of collectively significant goals of improvement, accumulation of effective potential, etc.). The specificity of the relevant structural organization of activities in a broader sense is to establish the relationship between the purpose of the activity and the action of its implementation, the attitude to the action, its assessment for itself in relation to this action. It was a special way of life existing, which provided an active position in its implementation, provided a subject of action, a subject of activity capable of reproducing a special social form of life in which attitudes and relation towards self (self-relations) become a necessary condition for its existence. The formation of socioprofessional activity of the future teacher is carried out in the process of activity, communication and interaction with the educational environment through active influence on the development of socio-professional environment, through the development of interpersonal communication and improvement of psychological and pedagogical training. In the modern system of social and professional training of future teachers, the main attention is mainly paid to the acquisition of knowledge by students in special subjects. As evidenced by the current state of development of psychological and pedagogical science, this approach is not effective enough for the professional activities of teachers and for the intensive formation of one's socio-professional activity.

\section{RESEARCH METHODOLOGY}

Investigating the peculiarities of the formation of socio-professional activity of the future teacher's personality in terms of their professional training, we use the known in the scientific literature general scheme and criterion for confirming or refuting the hypothesis in any social experiment:

Experimental group $\mathrm{X} 2-\mathrm{X} 1=\mathrm{A}$

Control group $\mathrm{X} 2-\mathrm{X} 1=\mathrm{B}$

Where $\mathrm{X} 1$ is the state of the system of the object being studied before the action of the pedagogical stimulus in the experimental group;

$\mathrm{X} 2$ - the state of the same system after the stimulus and the corresponding changes due to the action of the latter;

$\mathrm{X} 1$ and $\mathrm{X} 2$ - mean the initial and final states of a similar system in the control group.

The formal criterion for confirming or refuting the hypothesis in this case is the presence or absence of differences between the state of the experimental and control groups.
The study of the process of formation of socioprofessional activity of the future teacher is based on the results of the analysis of the dependence of personality development on the influence realized by the organizers, its content, methods, forms taking into account the influences of social factors. To diagnose the activity in the structure of the holistic personality of the future teacher, we used the following methods: the use of frequency distribution of grades and ranking of indicators of socio-professional activity of the individual according to the degree of their manifestation; determining the correlation galaxy of relationships of personality qualities that are studied, both the original elementary and generalized; calculation of the generalized indicator as a quantitative index of the level of development of socio-professional activity.

Based on the value of the index of socio-professional activity of the individual, we carried out a comparative sociological and pedagogical analysis of the level of development of socio-professional activity of the individual students in accordance with the areas of their activities in selected pedagogical factors.

The frequency distribution of assessments includes an ordinal scale for measuring personal qualities. This determines the content of the applied methods of mathematical statistics. The obtained result of the distribution of assessments based on the measurement scale used in the study of socio-professional activity, we present using tables and graphs. To generalize them, the calculation of the arithmetic mean (mathematical expectation) is used.

The formation of sample populations involves the use of the method of sample observation, which contains knowledge of objective laws, through which there are methods of cognition and practical action. In most cases, the methods of the sample are randomly selected units of the object, which is studied using the law of large numbers and surveys of groups of people. The application of probability theory, mathematical statistics can reproduce the statistical side of determination - the dependence of a particular feature of individual phenomena of the mass population on the necessary and random causes.

\section{RESEARCH RESULTS}

Experimental work on the problem of forming the social and professional activity of the personality of students of pedagogical higher educational institutions was started in 2004 on the basis of Volodymyr Vynnychenko Kirovohrad State Pedagogical University. 780 students of the Department of Pedagogy and Psychology, the Department of Natural Geography and the Department of Physical Education were involved in the experiment. Based on the application of the "ex post facto" method, two experimental and two control groups were formed. The experimental groups included students 
who are involved in such activities that serve as pedagogical conditions for the effective formation of social activity of future teachers. The control groups were formed by students who almost do not participate in such activities.

Psychological and pedagogical diagnostics, which partially establishes the level of personal activity, includes the study of socio-psychological and pedagogical conditions of high school development, observation of ways of communication of a particular student in the micro-society, the change of status among peers.

The most effective methods in making a psychological and pedagogical diagnosis were: observation in natural conditions, pedagogical consultations, taking into account the views of peers, individual conversations in specially created situations. Based on them, detailed psychological and pedagogical characteristics of each high school student who participated in the experiment were made. These results can be considered the initial (zero) slice of the level of personal activity.

In pedagogical research, models perform several functions: illustrative, translational, explanatory, prognostic.

The success of the pedagogical process depends on certain personality traits of the teacher-educator, so they are the basis of theoretical models. Personality quality is a long-standing characteristic that is manifested in the behavior of the individual in different situations. Professionally significant are the qualities of personality, which are manifested in a stable attitude to their profession, work, people, nature, things; a certain system of motives, forms and ways of professional role behavior.

In our study, we took into account the research $[1 ; 2 ; 3 ; 4]$. Ananiev B. G. identifies such personal characteristics of the teacher as a general high cultural and political development and a broad scientific worldview, an active attitude to the subject, which encourages students to work hard, individual approach and fair assessment of students, the desire to communicate [5].

Platonov K.K. [6] defines his model of the personality of the specialist through the understanding of the personality of the teacher as a dialectical unity of the general, special and individual, carrying out its structuring on this point of view. To the general properties of personality he includes ideological and political, moral, legal and aesthetic, which form the basis of individual consciousness of the individual; to special qualities associated with individual experience and professional activity. To special professional skills and abilities as personality traits Platonov K. K. includes cognitive, constructive, communicative, informational and organizational skills and abilities.
Using the approach proposed by Platono, K. K., we can offer a map of the teacher's personality from three main blocks:

1) general pedagogical qualities (professional orientation, respectively socially and professionally important personality traits: citizenship, love for children, interest in the profession, humanity, friendliness, communication);

2) professional qualities (theoretical and methodological training);

3) individual psychological qualities (pedagogical orientation in the specialty, psychological and pedagogical theoretical and practical training, development of pedagogical skills: cognitive, constructive, communicative, mental processes, development of pedagogical thinking, imagination and memory, emotional responsiveness (empathy), development of will, temperament culture).

Gonobolin F. N. divides the qualities that ensure the successful work of the teacher, the actual pedagogical abilities and accompanying properties. Among the professionally significant properties and qualities of the teacher's personality he includes pedagogical tact, ability to understand the student, organizational skills, ability to work creatively, etc. In addition to these professionally significant properties, Gonobolin, F. N. identifies personal qualities that ensure the effectiveness of pedagogical activities: confidence, determination, adherence to principles, perseverance, endurance, ingenuity, resilience [7].

The model of the teacher's personality is built on a general hierarchical principle: from the qualities that determine the moral state of the teacher and are not specific to pedagogical activities, to the qualities that are manifested in specific pedagogical situations. $\mathrm{He}$ believes that in the pedagogical structure of the teachereducator should be identified general civic qualities, moral and psychological, socio-perceptual, individual and psychological characteristics, practical skills and abilities: general pedagogical (informational, mobilization, developmental, orientational), general labor (constructive), organizational, research), communicative (communication with people of different ages), self-educational (systematization and generalization of knowledge, as well as their application in solving pedagogical problems and obtaining new information).

\section{RESULTS AND DISCUSSION}

To understand the peculiarities of the development of socio-professional activity of the future teacher, we distinguish several levels. Analyzing the development of socio-professional activity in accordance with a certain level, we focus on the features of different influences of 
educational activities on the growth of socio-professional activity.

We distinguish three levels of development of socioprofessional activity of the future teacher.

The first level is reproductive-contemplative. The content of this level is explained by the elementary entry of the student into the profession. One contemplates (gets acquainted) with its features, tries to identify himself with other students and the educational professional environment. There is an adaptation to the requirements of professional training. At least one of the values of the activity index falls within the values of this level. The numerical value of the interval on the measurement scale from 1.6 to 2.51

The second level is social and creative. It is characterized by the formation of social experience, professional growth, development and defense of their own position. It is determined by the numerical interval $2.51-4.1$

The third level is search. Students who belong to this level, fully identify with the peculiarities of professional activity, see the existing problems, try to solve them. Numerical range - from 4.1 to 5.0.

An important factor in the development of integral characteristics of a professional's personality is one's awareness of the need for change, transformation of one's inner world and the search for new opportunities for self- realization at work, ie the need to increase the level of professional consciousness.

According to Rubinstein S. L., self-awareness - is primarily a definition of their own way of life, awareness of their potential, prospects for personal and professional growth [8], which encourages constant experimentation, creative search, solving problems of social and professional development: choose - to feel free, on the one hand, and to be responsible for everything that happens and will happen, on the other.

An active desire to control oneself arises when one is aware of the need and possibilities of self-government. This happens objectively, without external pressure, with the gradual entry of the individual into independent life. The ability to self-government is formed on the basis of one's own assessment of the actual development of personal qualities and their comparison with similar qualities of one's peers or one's ideal. This comparison is aimed at the desired and achieved goal of being similar to peers and the chosen ideal. As a result, there is an adjustment in the hierarchy of the significance of qualities in the direction of convergence with the portrait of the reference group.

Experimental data and taking into account theoretical generalizations and conclusions allow us to propose certain criteria for the formation of socio-professional activity of the future teacher.

Table 1. Dynamics of frequency distribution of students of the experimental group according to the index of socioprofessional activity

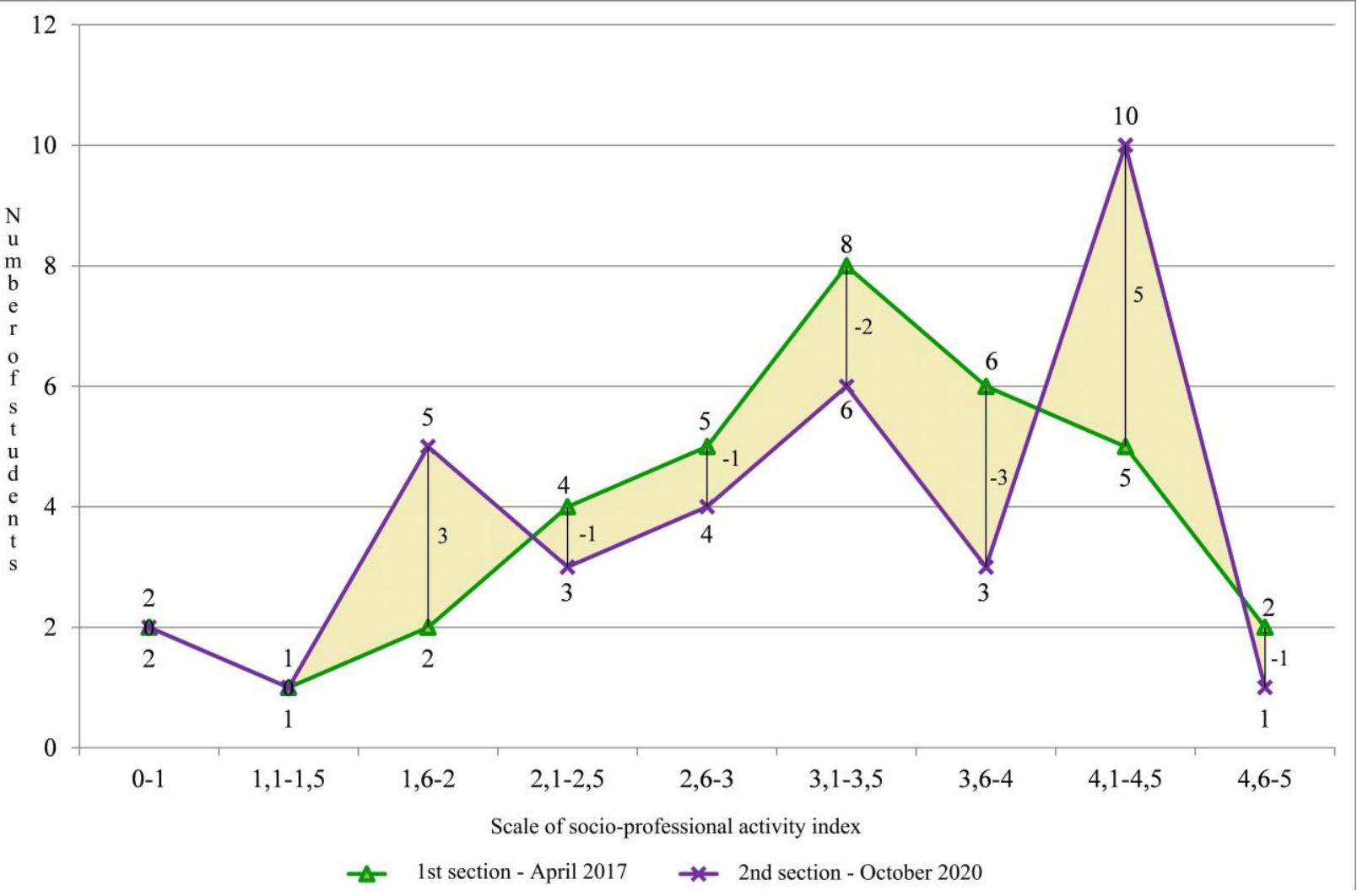


We consider social formation of personality as a complex process of adaptation of the younger generation to life, a certain social community. Therefore, in psychological and pedagogical publications, social maturity of a person is more often interpreted as a holistic cycle of individual development of a person, which includes childhood, youth and old age. This implies that there is a point of reference - the minimum social maturity of the individual. Personality is considered by pedagogues as an individual, specific entity. In philosophy, "singular" (separate, individual) refers to a concept that captures individual things, phenomena, which in turn are characterized by the corresponding spatial and temporal boundaries, corresponding to the quality [9].

We understand the criterion of "socio-professional orientation" as a qualitative characteristic of the development of the student's personality, which is determined by the manifestation of certain professional experience and social aspects of individual consciousness. Its indicators are: expression of personal self-awareness; desire for socio-professional development; socio-professional self-determination; persistence in the realization of desires and aspirations; faith and confidence in the chosen goal.

Babansky Ju. K. designs a model of the teacher's personality in accordance with the main directions of his activity, on the one hand, as a subject teacher, and on the other - as an educator of the student body [10].

The criterion "personal self-realization" is the level of personal aspirations and opportunities in socioprofessional development. We distinguish the following indicators: personal maturity; social responsibility; selfanalysis and self-improvement; the relationship between the development of aspirations and opportunities; personal motivations; social expectations and forecasts; social communication.

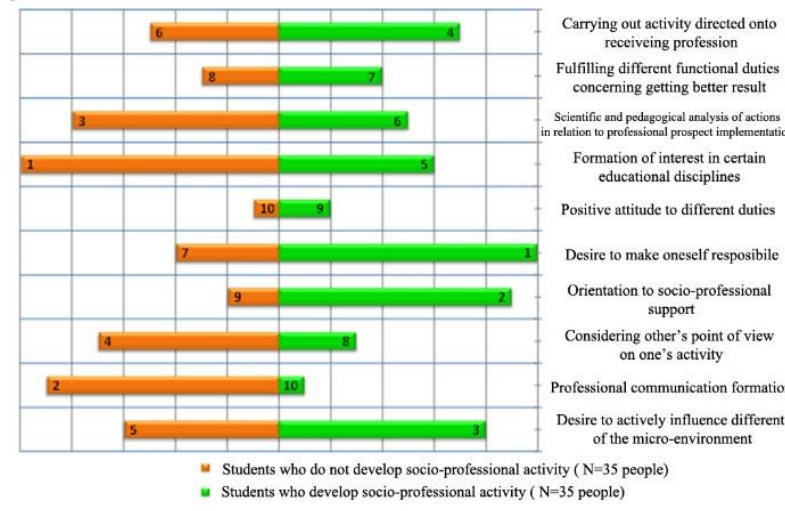

Figure 1 Rank analysis of the content of indicators of socio-professional activity

The criterion of "socio-professional motivation" of the individual is a socio-professional quality that characterizes the stability of motives for professional activity. Indicators of this criterion are: socioprofessional self-realization; motives of self-realization of the person; motives for socio-professional growth; motives of socially useful activity.

\section{CONCLUSIONS}

If we want to educate a professionally active specialist, we need one to tell and show not what one knows and can, but what one does not know and can not, and seek to close gaps in knowledge. To do this, the content of education in higher pedagogical education should be such that the future teacher in the early stages of learning could gain comprehensive knowledge and skills, which are dominated by the categories of "person", "personality", "pedagogical system", "pedagogical communication", " pedagogical culture ". A thorough theoretical and methodological block will prepare the basis for the university period of study to become a certain alternative to traditional school practice, predicting the life of the future teacher, which corresponds to the humanistic concept of education. In parallel, it is necessary to create such educational conditions that the student has a need for active interaction with pedagogical knowledge and experience. Constantly modified in the interaction of the future teacher with specific real pedagogical problems, the content is subjected, gets an individual-personal orientation.

\section{REFERENCES}

[1] Oleg Barabash, Andrii Musienko, Spartak Hohoniants, Oleksand Laptiev, Oleg Salash, Yevgen Rudenko and Alla Klochko (2021), "Comprehensive Methods of Evaluation of Efficiency of Distance Learning System Functioning", International Journal of Computer Network and Information Security, Vol. 13, No. 1, pp. 16-28. DOI: $10.5815 /$ ijcnis.2021.01.02

[2] Dawn Carmichael and Jacqueline Archibald (2019), "A Data Analysis of the Academic use of Social Media", International Journal of Information Technology and Computer Science, Vol. 11, No. 5, pp. 1-10. DOI: 10.5815/ijitcs.2019.05.01

[3] Mubasher Hassan and Tabasum Mirza (2021), "The Digital Literacy in Teachers of the Schools of Rajouri (J\&K)-India: Teachers Perspective”, International Journal of Education and Management Engineering, Vol. 11, No. 1, pp. 2840. DOI: 10.5815/ijeme.2021.01.04

[4] Antti Herala, Antti Knutas, Erno Vanhala and Jussi Kasurinen (2017), "Experiences from Video Lectures in Software Engineering Education", International Journal of Modern Education and Computer Science, Vol. 9, No. 5, pp. 17-26. DOI: 10.5815/ijmecs.2017.05.03

[5] Anan'jev, B.G. (1968), Chelovek kak predmet 
poznanija [Human as a subject of knowledge], LGU Publ.

[6] Platonov, K. K. (1986), Struktura $i$ razvitie lichnosti [Structure and development of personality], Nauka, Moscow.

[7] Gonobolin, F. N. (1965), Kniga ob uchitele [A book about teacher], Prosveshhenie, Moscow.

[8] Makarova, N. I. (2004), Violence - Non-Violence in Modern Education (or Pedagogy of NonViolence as a Philosophical Problem), Makarova N. I., Nalyvaiko N. V., Filosofija obrazovanija, No. 10.

[9] Valerii V. Radul, Yaroslav V. Haleta, Rostyslav O. Liashenko, Olha S. Radul and Olha M. Tkachenko (2020), "Social maturity as integrative quality of young teacher's personality", ASTRA Salvensis, Supplement no. 1, pp. 235-251.

[10] Babansky Ju. K. (1982), Problemy povyshenija jeffektivnosti pedagogicheskih issledovanij [Problems of increasing the effectiveness of educational research], Pedagogika, Moscow. 